Editorial

\title{
Media Studies for a Mediatized World: Rethinking Media and Social Space
}

\author{
André Jansson * and Johan Lindell \\ Department of Geography, Media and Communication, Karlstad University, 65188 Karlstad, Sweden; E-Mails: \\ andre.jansson@kau.se (A.J.), johan.lindell@kau.se (J.L.) \\ * Corresponding author
}

Submitted: 26 March 2018 | Published: 25 May 2018

\begin{abstract}
This editorial introduces a thematic issue on "Rethinking Media and Social Space". By critically rethinking the relationship between media and social space this issue takes initial steps towards ensuring that media studies is appropriate for a mediatized world. Contemporary societies are permeated by media that play important roles in how people maneuver and position themselves in the social world. Yet, analyses of media-related social change too often fail to engage with the complex and situated nature of power relations. This editorial highlights three enduring problems: (1) the annihilation of the socially structured and structuring role of media technologies and practices; (2) the conflation of inherent social capacities of media technologies and discourses with existing mediations of power, and (3) the reduction of social space to one predominant dimension which overshadows all other forms of social power that media technologies, discourses, and practices are part of. As a response to these problems-and in bringing together the arguments of the five articles included in the thematic issue-this editorial calls for sociologized approaches to media technologies, discourses, and practices.
\end{abstract}

\section{Keywords}

mediatization; media discourse; media practice; media sociology; media technology; power; social space

\section{Issue}

This editorial is part of the issue "Rethinking Media and Social Space", edited by André Jansson and Johan Lindell (Karlstad University, Sweden).

(C) 2018 by the authors; licensee Cogitatio (Lisbon, Portugal). This article is licensed under a Creative Commons Attribution 4.0 International License (CC BY).

\section{Introduction}

There are several ways to study the relations between media and social space. Examples include Bourdieusian studies of the dispersion of media repertoires in a class structure; Lefebvrian analyses of the significance of media for the social production of spaces and places, and their symbolic-material textures; social constructivist interpretations of mediation as a form of world making (following Berger and Luckmann), and mediatization as a form of social structuration (in the Giddensian sense). Although attuned differently, these views converge in that they address the role of media in social reproduction and change. They tease out the relations between single instances of social and/or discursive practice and overarching power structures in society. Such relations occur in complex ways and on different levels. First, there are a growing number of techno-social machiner- ies that in various, increasingly automated ways premediate (Grusin, 2010) the cultural preferences and social practices of different groups. Second, they unfold through discursive constructions of social and spatial relations. Third, they are established through the classified and classifying media practices of different social groups. In times of connective and locative media (Van Dijck, 2013; Wilken \& Goggin, 2015), and what we may ultimately describe as an algorithmic culture (Striphas, 2015), these levels become increasingly interdependent making social power relations at once more fluid as well as technologically dependent. This implies that media and social space become even more closely interwoven than before.

Still, it is our contention that the term social space per se has not been sufficiently problematized and theorized in media and communication studies. There is a tendency either to overlook questions of how social power 
is mediated (often stemming from a lack of contextualization) or to treat social space reductively. This is particularly problematic in times when media change is assumed to have an almost revolutionary impact on society and culture. Against this backdrop, this thematic issue of Media and Communication brings together prominent scholars to shed light on the relationships between media and social space-both theoretically and empirically. The articles assess the relevance of various conceptual frameworks and explore the changing modes of social reproduction and change that characterize our technologically mediated culture and society. In this introduction, we will initially discuss why there is a growing need for media scholars to problematize social space before going on to introduce and collate the key arguments of the five articles within this thematic issue.

\section{Three Reasons to Rethink Media and Social Space}

Since we conceive of power as something relational it is also an inherently mediated matter. As Williams (1976) discusses in his Keywords, modern thought has conceived of mediation predominantly as an intermediary form of action to "bring about reconciliation or agreement" between different parties (p. 206). But it is also, and at the same time, a process that actualizes and makes visible relations of domination, and carries the ideologies that legitimate such relations. As such, power cannot exist without mediation. This manifests in concrete situations of communicative exchange, where the discursive construction of speech acts excludes and includes different interlocutors. We can also see it on the societal level, where culture operates as a "mediation of society" (Williams, 1977, p. 99), meaning that power relations are not external to culture but are an integral and continuously molded part of it. However, as Williams also argues, there is a risk that mediation-understood as the "intermediary"-invokes the separation of categories that are not easy to distinguish, such as reality vs. representation and base vs. superstructure. Hence, while we should take the fundamental role of mediation for the (re)production of social power relations seriously, we should be cautious not to reproduce simplified views of how these processes occur, for instance in terms of linear media effects or ideological manipulation.

While the above point may seem quite old, converging with classical debates that have been covered in textbooks such as McQuail's (2010) Mass Communication Theory, we argue that media and communication studies still too often operate with ontological and epistemological frameworks that fail to grasp the complex ways in which media-understood as technologies of mediation-emerge through and play into social power relations. This is a particularly critical issue today, given that media and communication technologies hold an increasingly ubiquitous presence in people's everyday lives, mediatizing as well as mediating all kinds of social relations (see, e.g., Couldry \& Hepp, 2016).

With this thematic issue, we seek to address three enduring problems that we have detected in current media research, especially related to the impact of new media technologies and forms. ${ }^{1}$ The first problem concerns the annihilation of the socially structured and structuring role of media technologies and practices. In contemporary discussions on how media change society and culture, there is a tendency to generalize new developments across social space without problematizing whether and how they are premised on certain power geometries. While the problems of stratification (in the "vertical" sense of social space) and differentiation (in the "horizontal" sense) have been acknowledged, for example, in mediatization theory (e.g., Ekström, Fornäs, Jansson, \& Jerslev, 2016), theoretical concepts are all too often introduced and implemented without assessment of their applicability to different social settings and social groups. Such uncritical reiterations of theoretical axioms tend to conceal how mediation (re)produces power relations.

The second problem concerns the conflation of inherent social capacities of media technologies and discourses with existing mediations of power. This problem implies that the power of mediation is exaggerated rather than annihilated. It is particularly obvious in critical accounts of how new media technologies affect structures of domination on a larger scale, such as the pervasive commoditizing impact of social media on society and culture, as well as in discourse analytical approaches to how certain new media formats may influence relations between societies and cultures on a larger scale. These types of studies are often based on sophisticated approaches to technological and/or textual affordances or logics but fail to validate their claims in relation to the actual social conditions of media use.

The third problem concerns the reduction of social space to one predominant dimension that overshadows all other forms of social power that media technologies, discourses, and practices are part of. This problem can be detected above all in media studies pertaining to particular cultural communities or identities, for example in terms of gender, sexuality, ethnicity, or class. While there is a rich body of research providing in-depth analyses of how media sustain or interrupt power relations based on people's positionalities in social space there is also a risk that the focus on one particular group or community obscures other power dimensions which may also be at work. The solution to this problem would be a stronger engagement with intersectionality, for instance in the spirit of Skeggs' (1997) work on gender and working-class culture, and the multidimensional nature of social space proposed by Bourdieu who, contrary to popular belief, was sensitive to how social and geographical space overlap and intermingle (2000, p. 134).

\footnotetext{
${ }^{1}$ Since there is not enough space in this editorial to formulate a more elaborate critique of particular works (and thus treat them in a fair and justified manner) we have refrained from including any references to studies that would be representative of the problems we mention.
} 
In sum, these problems point to an overarching need to sociologize (certain strands of) media studies. While it would be naive to expect that all studies should pay equal attention to all these issues, we claim that sociological sensitivity is especially important in analyses that deal with media related change. In the following section, we discuss how this endeavor is handled in the five articles presented in this thematic issue.

\section{How to Sociologize Media Technologies, Discourses, and Practices}

The five articles included in this thematic issue all address the concerns outlined above. They come together in a joint effort to sociologize media-as either technologies, discourses or the practices connected to them-and thus to grasp the social power relations associated with media related change.

Abeele, De Wolf and Ling (2018) start off the issue by theorizing mobile media and social space. Drawing on Giddens' structuration theory they provide an exposé on the role of mobile media in everyday life. The Giddensian view allows Abeele et al. (2018) and her colleagues to unravel key micro and macro dynamics that reshape social life in our digitized and mediatized world. Their argument is that the present media landscape, the norms and practices connected to it, incurs a heavy burden for the individual media user - who has to manage and control their communication, and be aware of the consequences of their actions in a networked and surveilled everyday life.

Fast (2018), in turn, shifts our attention to corporate technology discourse and how the transnational information and communication technology (ICT) companies Ericsson, IBM and Huawei construct the notion of media indispensability in their external communication. Despite the social costs and the power dynamics that come with the mediatized and mobile society, the discursive trope of media indispensability is mobilized on the part of ICT companies as the key to the "good life". Fast's contribution provides not just a timely call for a "discursive turn" in mediatization studies but also invites readers to question the prevailing discourse of all-encompassing connectivity and how it represents and annihilates certain groups and places in society.

Chan and Humphreys (2018) provide an empirical account of how Californian Uber drivers manoeuver and make sense of their quantified and surveilled ways of making a living in the "gig economy". They provide an account of how media re-negotiate social space at the micro level, in the everyday lives of people in particularly mediatized and sometimes precarious lines of work. Uber drivers, Chan and Humphreys (2018) argue, have developed a "distinct algorithmic imaginary" which shapes their practices and thus the production of social space. The article thus contributes to a more detailed and practice-oriented understanding of the increasingly pervasive datafication of social space.
We have argued that much media and communication research provides sweeping descriptions of how mobile and digital media have fundamentally altered social life, and thus tends to overlook how people make sense of media in everyday life, and how media practices unfold therein. Bengtsson's article is, therefore, an important contribution. Her focus is on the "mundane negotiations and practices "related to the "good life" with media. In using qualitative interviews and a sociophenomenological approach Bengtsson (2018) has been able to unveil the relations between the "ethics of the ordinary" and sensorial experiences related to the media. The study illustrates the concrete ways in which media are used to organize social space and how they are positioned in relation to the course of daily life.

Finally, Hartley (2018) mobilizes the Bourdieusian view of social space-a space of class relations wherein agents endowed with different ways of relating to the social world (habitus) form distinct lifestyles and media repertoires. In her interview study with young Danes Hartley (2018) shows how the possession or dispossession of cultural capital shapes people's relation to news and journalism. Her article adds to the body of Bourdieusian studies of the Scandinavian societies which converge in that they illustrate the explanatory power of the notion of social space for understanding and explaining media practice-even in so-called "egalitarian" countries.

Taken together, the five articles take important steps towards a media studies that is more sensitive to the ways in which media become a part of social power geometries. Social space, we argue, is a particularly fruitful concept for such studies, especially in times marked by strong popular and academic belief in media as the driver of social change. It concerns how media technologies and their logics shape the ways people think about and position themselves in social space; how discourses about media change contribute to the normalization of certain ideologies of social development (and the agents of such development), and how media are embedded in place and space through classified and classifying forms of everyday practice. A media studies that can properly come to terms with, and understand our mediatized worlda networked, datafied, digitized, surveilled, and not least a fundamentally unequal world-should critically rethink the relationship between media and social space. This thematic issue takes one step in that direction.

\section{Conflict of Interests}

The authors declare no conflict of interests.

\section{References}

Abeele, M. V., De Wolf, R., \& Ling, R. (2018). Mobile media and social space: How anytime, anyplace connectivity structures everyday life. Media and Communication, 6(2), 5-14. 
Bengtsson, S. (2018). Sensorial organization as an ethics of space: Digital media in everyday life. Media and Communication, 6(2), 39-45.

Bourdieu, P. (2000). Pascalian meditations. Cambridge: Polity.

Chan, N. K., \& Humphreys, L. (2018). Mediatization of social space and the case of Uber drivers. Media and Communication, 6(2), 29-38.

Couldry, N., \& Hepp, A. (2016). The mediated construction of reality. Cambridge: Polity.

Ekström, M., Fornäs, J., Jansson, A., \& Jerslev, A. (2016). Three tasks for mediatization research: Contributions to an open agenda. Media, Culture \& Society, 38(7), 1090-1108.

Fast, K. (2018). A discursive approach to mediatisation: Corporate technology discourse and the trope of media indispensability. Media and Communication, 6(2), 15-28.

Grusin, R. (2010). Premediation: Affect and mediality after 9/11. Basingstoke: Palgrave Macmillan.
Hartley, J. M. (2018). 'It's something posh people do': Digital distinction in young people's cross-media news engagement. Media and Communication, 6(2), 46-55.

McQuail, D. (2010). McQuail's mass communication theory. London: Sage.

Skeggs, B. (1997). Formations of class \& gender: Becoming respectable. London: Sage.

Striphas, T. (2015). Algorithmic culture. European Journal of Cultural Studies, 18(4/5), 395-412.

Van Dijck, J. (2013). The culture of connectivity: A critical history of social media. Oxford: Oxford University Press.

Wilken, R., \& Goggin, G. (Eds.). (2015). Locative media. London: Routledge.

Williams, R. (1976). Keywords: A vocabulary of culture and society. London: Fontana Press.

Williams, R. (1977). Marxism and literature. Oxford: Oxford University Press.

\section{About the Authors}

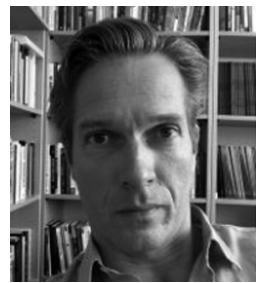

André Jansson is a professor of Media and Communication Studies and director of the Geomedia Research Group at Karlstad University, Sweden. His most recent monographs are Mediatization and Mobile Lives: A Critical Approach (Routledge, 2018) and Cosmopolitanism and the Media: Cartographies of Change (with M. Christensen, Palgrave Macmillan, 2015). Recent articles have been published in journals such as Annals of Tourism Research, Communication Theory, European Journal of Cultural Studies, Media, Culture \& Society, and New Media \& Society.

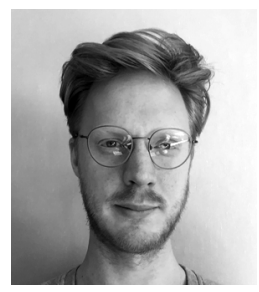

Johan Lindell is a senior lecturer in Media and Communication Studies at Karlstad University, Sweden. His research interests include the sociology of Pierre Bourdieu, media use, and social- and cultural stratification. He has previously published his research in, for example, New Media \& Society, Media, Culture \& Society, Communication Theory, and European Journal of Communication. 